\title{
Sistem Pendukung Keputusan Seleksi Bantuan Siswa Miskin Menerapkan Kombinasi Metode SAW dan ROC
}

\author{
Andri Yunaldi \\ Prodi Manajemen Informatika, AMIK Kosgoro, Padang, Indonesia \\ Email: andriyunaldi261168@gmail.com
}

\begin{abstract}
Abstrak
Sistem pendukung keputusan (SPK) merupakan sistem yang membantu pengambil keputusan dalam hal ini kepala sekolah, agar keputusan yang dihasilkan dinilai efektif dan tepat untuk menyelesaikan permasalahan yang dihadapi. Khususnya dalam penetapan pemberian bantuan siswa miskin, penetapan kriteria-kriteria di tujukan agar penerima bantuan sesuai dengan tujuan pemberian bantuan itu sendiri. Pada penelitian ini, penulis menerapkan kombinasi metode SAW dan ROC dalam penyeleksian penerima bantuan. ROC (Rank Order Centroid) merupakan metode yang dapat menghasilkan nilai bobot, sedangkan Simple Additive Weighting (SAW) merupakan metode yang digunakan untuk perangkingan terhadap calon penerima bantuan siswa miskin yang dijadikan alternatif. Hasil penelitian diharapkan memberikan kontribusi pada pengembangan ilmu pengetahuan, khususnya kepala sekolah dalam keputusan seleksi penerima bantuan siswa miskin.
\end{abstract}

Kata Kunci: BSM, Rank Order Centroid, ROC, Simple Additive Weighting, SAW, SPK

\begin{abstract}
Decision support system (DSS) is a system that helps decision makers in this case the principal, so that the decisions produced are considered effective and appropriate to solve the problems faced. Specifically in determining the provision of assistance to poor students, the determination of the criteria is aimed at making the recipient of the assistance in accordance with the purpose of the assistance itself. In this study, the authors applied a combination of SAW and ROC methods in selecting beneficiaries. ROC (Rank Order Centroid) is a method that can produce weight values, while Simple Additive Weighting (SAW) is a method used to rank poor prospective student assistance recipients as an alternative. The results of the study are expected to contribute to the development of science, especially the principal in the selection decision for recipients of poor student assistance.
\end{abstract}

Keywords: BSM, Rank Order Centroid, ROC, Simple Additive Weighting, SAW, DSS

\section{PENDAHULUAN}

Beasiswa merupakan salah satu bantuan dalam bidang keuangan yang diberikan baik kepada perorangan maupun lembaga yang bertujuan dalam memberikan keringanan dalam pembayaran biaya pendidikan yang ditempuh oleh siswa ataupun lembaga pendidikan. Pemberian beasiswa merupakan salah satu apresiasi dari suatu lembaga kepada siswa didik yang kurang mampu dengan tujuan dapat memotivasi peserta didik (siswa) untuk lebih semangat dalam menempuh pendidikan. Pemberian beasiswa yang tepat mampu memotivasi peserta didik pada suatu lembaga pendidikan, sebaliknya bila beasiswa yang diberikan salah sasaran maka yang terjadi adalah peningkatan prestasi yang diharapkan tidak akan terlihat dari peserta didik.

Agar pemberian beasiswa tepat maka penyeleksian dalam penerimaan beassiwa harus lebih baik. Saat ini keputusan yang harus dikeluarkan terhadap penerima beasiswa oleh lembaga pendidikan masih dinilai kurang tepat, karena masih bersifat subjektif, didasarkan faktor kekeluargaan, hubungan kedekatan dan lainnya, bukan dikarenakan kurang mampu, prestasi yang pernah di capai ataupun keaktifan dalam berorganisasi di lembaga pendidikan, sehingga ketercapaian dari manfaat pemberian beasiswa kurang dirasakan. Untuk itu diperlukan suatu sistem yang memberikan bantuan dukungan terhadap keputusan yang dihasilkan oleh pihak lembaga pendidikan. Sistem ini dikenal dengan nama Sistem Pendukung Keputusan (SPK)[1], [2]. Hasil dukungan keputusan yang diberikan sesuai dengan penyeleksian terhadap kriteria yang ditentukan, misalnya ranking kelas, nilai rata-rata, rendahnya pendapatan orang tua.

Penerapan sistem pendukung keputusan dalam pemberian dukungan terhadap keputusan pimpinan lembaga bukan merupakan hal yang baru disaat ini. Telah banyak penelitian yang dilakukan oleh kalangan peneliti, terkait dengan suatu keputusan yang akan di ambil oleh pimpinan. Banyak penerapan metode yang dilakukan untuk membuat hasil keputusan menjadi lebih objektif, seperti penerapan metode Simple Additive Weighting[3], [4], ELECTRE[5], [6], EXPROM2[7], [8], Preference Selection Index (PSI)[9]-[11], ARAS[12], [13].

Pada penelitian yang dilakukan oleh Imam Saputra, penerapan ELECTRE dalam sistem pendukung keputusan belum menggunakan metode pembobotan. Electre hanya digunakan untuk mendapatkan hasil dari penyeleksian terhadap alternatif yang ada[5]. Mesran pada tahun 2019, menggunakan metode pembobotan Rank Order Centroid untuk mendapatkan nilai bobot, penerapan ROC dikombinasikan dengan metode ARAS, sehingga hasil yang diperoleh efektif memberikan keputusan yang tepat dalam penilaian kinerja karyawan[14].

Pada penelitian ini, penulis menggunakan metode SAW dan mengkombinasikan dengan metode ROC dalam mendapatkan keputusan tentang calon penerima bantuan siswa miskin. Hasil yang diharapkan agar keputusan yang diberikan efektif dan efisien dalam penentuan siswa yang mendapatkan bantuan tersebut.

\section{METODE PENELITIAN}




\subsection{Sistem Pendukung Keputusan}

Sistem Pendukung Keputusan, atau dikenal dengan istilah SPK, merupakan sistem informasi yang dapat menghasilkan keputusan yang efektif, untuk membantu manager dalam menyelesaikan permasalahan, baik yang sifatnya terstruktur maupun tidak terstruktur[15]-[17]. Penerapan sistem pendukung keputusan sangat membantu pimpinan dalam menghasilkan keputusan. Saat ini banyak aplikasi-aplikasi yang digunakan oleh masyarakat dalam memberikan keputusan yang tepat dalam menyelesaikan suatu permasalahan.

\subsection{Rank Order Centroid(ROC)}

Metode Rank Order Centroid (ROC) merupakan metode yang dapat menghasil pembobotan terhadap sejumlah kriteria sesuai dengan tingkat kepentingan dari kriteria yang ditetapkan. Hasil yang diberikan oleh metode ROC cukup membantu pengambil keputusan dalam penetapan bobot dari suatu kriteria. Dalam proses kerjanya metode ROC cukup mudah, kriteria pertama merupakan kriteria yang lebih penting dibanding kriteria kedua, sedangkan kriteria kedua merupakan kriteria yang lebih penting dibandingkan kriteria ketiga, begitu selanjutkan terhadap kriteria keempat dan kelima[14], [18], [19].

\subsection{Simple Additive Weighting(SAW)}

Simple Additive Weighting (SAW) merupakan metode pemeringkatan yang cara kerjanya menambahkan hasil perkalian bobot dari kriteria dengan nilai alternatif yang ada. Penerapan metode SAW cukup sederhana, namun hasil yang diberikan bersifat objektif dalam menghasilkan alternatif terbaik. Alternatif terbaik diperoleh dari nilai pemeringkatan yang tertinggi dibandingkan dengan alternatif yang lainnya[3], [20]-[22].

\section{ANALISA DAN PEMBAHASAN}

Bantuan siswa miskin merupakan satu dari beberapa cara yang digunakan kepala sekolah untuk memberikan keringanan atas biaya pendidikan yang harus dikeluarkan oleh siswa yang tidak mampu. Pada penerapannya menggunakan sistem pendukung keputusan, diperlukan calon alternatif terhadap penerima bantuan siswa miskin tersebut. Kriteria yang ditetapkan sebagai syarat untuk mendapatkan bantuan siswa miskin perlu ditetapkan oleh kepada sekolah, sehingga hasil yang didapat terbebas dari kesalahan.

Berikut merupakan kriteria-kriteria yang ditetapkan yang terlihat pada tabel 1 dan alternatif calon penerima bantuan siswa miskin pada tabel 2 .

Tabel 1. Kriteria Bantuan Siswa Miskin

\begin{tabular}{lll}
\hline Kriteria & Keterangan & Jenis \\
\hline $\mathrm{C}_{1}$ & Penghasilan Orang Tua & Cost \\
$\mathrm{C}_{2}$ & Tanggungan Orang Tua & Benefit \\
$\mathrm{C}_{3}$ & Nilai Kehadiran & Benefit \\
$\mathrm{C}_{4}$ & Nilai Rata Rata & Benefit \\
$\mathrm{C}_{5}$ & Peringkat Kelas & Cost \\
\hline
\end{tabular}

Tabel 1, merupakan kriteria yang ditetapkan dalam penyeleksian bantuan siswa miskin. Dalam tabel tersebut berlum terdapat nilai bobot atau belum didefinisikan nilai bobot untuk tiap-tiap kriteria. Penerapan metode ROC bertujuan untuk mendapatkan hasil bobot dari kriteria yang ditentukan tersebut. Penerapan metode ROC secara umum dengan menggunakan persamaan 1 untuk mendapatkan hasil bobot, sebagai berikut:

$$
W_{m}=\frac{1}{m} \sum_{1=1}^{m}\left(\frac{1}{i}\right)
$$

Dari persamaan 1 di atas, maka diperoleh hasil seperti dibawah ini:

$$
\begin{aligned}
& W_{1}=\frac{1+\frac{1}{2}+\frac{1}{3}+\frac{1}{4}+\frac{1}{5}}{5}=0,457 \\
& W_{2}=\frac{0+\frac{1}{2}+\frac{1}{3}+\frac{1}{4}+\frac{1}{5}}{5}=0,257 \\
& W_{3}=\frac{0+0+\frac{1}{3}+\frac{1}{4}+\frac{1}{5}}{5}=0,156 \\
& W_{4}=\frac{0+0+0+\frac{1}{4}+\frac{1}{5}}{5}=0,090
\end{aligned}
$$


JURNAL MEDIA INFORMATIKA BUDIDARMA, Vol 3, No 4, Oktober 2019

ISSN 2614-5278 (media cetak)

ISSN 2548-8368 (media online)

Hal 376-380 | DOI: 10.30865/mib.v3i4.1511

$W_{5}=\frac{0+0+0+0+\frac{1}{5}}{5}=0,040$

Untuk bobot $\mathrm{C} 1$ diperoleh nilai sebesar 0.457 , bobot $\mathrm{C} 2$ sebesar 0.257 , bobot $\mathrm{C} 3$ sebesar 0.156 , bobot C4 sebesar 0.090 dan bobot C5 sebesar 0.040.

Pada tabel 2, merupakan calon penerima bantuan siswa miskin, yang merupakan alternatif yang dipilih dari beberapa siswa yang kurang mampu.

Tabel 2. Alternatif Calon Penerima Bantuan Siswa Miskin

\begin{tabular}{llllll}
\hline Alternatif & $\left(\mathrm{C}_{1}\right)$ & $\left(\mathrm{C}_{2}\right)$ & $\left(\mathrm{C}_{3}\right)$ & $\left(\mathrm{C}_{4}\right)$ & $\left(\mathrm{C}_{4}\right)$ \\
\hline $\mathrm{A}_{1}$ & 2900000 & 4 & 90 & 80 & 6 \\
$\mathrm{~A}_{2}$ & 2500000 & 3 & 85 & 82 & 5 \\
$\mathrm{~A}_{3}$ & 3150000 & 2 & 90 & 85 & 7 \\
$\mathrm{~A}_{4}$ & 2200000 & 4 & 85 & 88 & 3 \\
$\mathrm{~A}_{5}$ & 3200000 & 3 & 90 & 89 & 5 \\
$\mathrm{~A}_{6}$ & 2900000 & 3 & 100 & 86 & 4 \\
$\mathrm{~A}_{7}$ & 2100000 & 4 & 100 & 79 & 7 \\
$\mathrm{~A}_{8}$ & 2900000 & 3 & 80 & 80 & 8 \\
$\mathrm{~A}_{9}$ & 2750000 & 2 & 90 & 82 & 4 \\
$\mathrm{~A}_{10}$ & 2850000 & 2 & 100 & 81 & 5 \\
\hline
\end{tabular}

Pada tabel 2 merupakan calon alternatif penerima bantuan yang dapat langsung dijadikan sebagai data dari rating kecocokan atau sebagai nilai dari matrik keputusan (Xij). Berikut nilai dari matrik keputusan Xij.

$\mathrm{Xij} \quad\left|\begin{array}{lllll}2900000 & 4 & 90 & 80 & 6 \\ 2500000 & 3 & 85 & 82 & 5 \\ 3150000 & 2 & 90 & 85 & 7 \\ 2200000 & 4 & 85 & 88 & 3 \\ 3200000 & 3 & 90 & 89 & 5 \\ 2900000 & 3 & 100 & 86 & 4 \\ 2100000 & 4 & 100 & 79 & 7 \\ 2900000 & 3 & 80 & 80 & 8 \\ 2750000 & 2 & 90 & 82 & 4 \\ 2850000 & 2 & 100 & 81 & 5\end{array}\right|$

Selanjutnya, berdasarkan matrik keputusan Xij, dengan menggunakan persamaan ke 2 dan ke tiga, dilakukan normalisasi terhadap matrik keputusan Xij.

Pada persamaan ke 2, digunakan untuk jenis kriteria benefit.

$$
R_{i j}=\frac{X_{i j}}{\operatorname{Max} X_{i j}}
$$

Pada persamaan ke 3, digunakan pada kriteria cost.

$$
R_{i j}=\frac{\operatorname{Min} X_{i j}}{X_{i j}}
$$

Hasil dari matrik yang ternormalisasi (Rij) yaitu:

\begin{tabular}{l|lllll} 
& & & & \\
Rij & 0.724 & 1.000 & 0.900 & 0.899 & 0.500 \\
0.840 & 0.750 & 0.850 & 0.921 & 0.600 \\
0.667 & 0.500 & 0.900 & 0.955 & 0.429 \\
0.955 & 1.000 & 0.850 & 0.989 & 1.000 \\
0.656 & 0.750 & 0.900 & 1.000 & 0.600 \\
0.724 & 0.750 & 1.000 & 0.966 & 0.750 \\
1.000 & 1.000 & 1.000 & 0.888 & 0.429 \\
0.724 & 0.750 & 0.800 & 0.899 & 0.375 \\
0.764 & 0.500 & 0.900 & 0.921 & 0.750 \\
0.737 & 0.500 & 1.000 & 0.910 & 0.600
\end{tabular} \mid

Pada langkah akhir dilakukan dengan menjumlahkan hasil perkalian Rij dengan bobot (W) dengan menggunakan persamaan berikut ini: 


$$
V_{i}=\sum_{j=1}^{n} W_{j} \cdot R_{i j}
$$

Hasil perhitungan dapat dilihat pada tabel 3, sebagai berikut:

Tabel 3. Hasil Preferensi akhir

\begin{tabular}{lll}
\hline Alternatif & Nilai Vi & Peringkat \\
\hline $\mathrm{A}_{7}$ & 0.967 & 1 \\
$\mathrm{~A}_{4}$ & 0.955 & 2 \\
$\mathrm{~A}_{1}$ & 0.829 & 3 \\
$\mathrm{~A}_{2}$ & 0.816 & 4 \\
$\mathrm{~A}_{6}$ & 0.797 & 5 \\
$\mathrm{~A}_{5}$ & 0.747 & 6 \\
$\mathrm{~A}_{8}$ & 0.744 & 7 \\
$\mathrm{~A}_{9}$ & 0.731 & 8 \\
$\mathrm{~A}_{10}$ & 0.727 & 9 \\
$\mathrm{~A}_{3}$ & 0.677 & 10 \\
\hline
\end{tabular}

Hasil perhitungan pada tabel 3, dapat dilihat bahwa siswa dengan alternatif $A_{7}>A_{4}>A_{1}>A_{2}>A_{6}>A_{5}>A_{8}>A_{9}>A_{10}>A_{3}$, sehingga dapat diputuskan ke 5 siswa yang dengan peringkat nilai tertinggi dapat diberikan bantuan siswa miskin.

\section{KESIMPULAN}

Penerapan metode Rank Order Centroid (ROC) untuk menghasilkan nilai bobot dari tiap-tiap kriteria diperoleh dengan cukup sederhana, namun dapat memberikan tingkatan nilai yang baik dari tiap-tiap kriteria yang didefinisikan. Nilai bobot kriteria yang diperoleh dari metode ROC digunakan dalam metode Simple Additive Weighting (SAW) dalam penyeleksian calon penerima bantuan siswa miskin. Hasil yang didapat cukup baik, terbebas dari keputusan subjektif dari kepala sekolah dalam keputusan yang dihasilkan.

\section{REFERENCES}

[1] S. Kusumadewi, S. Hartati, A. Harjoko, and R. Wardoyo, Fuzzy Multi-Attribute Decision Making (Fuzzy MADM). Yogyakarta: Graha Ilmu, 2006.

[2] D. Nofriansyah, Konsep Data Mining Vs Sistem Pendukung Keputusan. 2015.

[3] S. H. Sahir, R. Rosmawati, and K. Minan, "Simple Additive Weighting Method to Determining Employee Salary Increase Rate," Int. J. Sci. Res. Sci. Technol., vol. 3, no. 8, pp. 42-48, 2017.

[4] Rusdiansyah, "Analisis Keputusan Menentukan Jurusan Pada Sekolah Menengah Kejuruan Dengan Metode Simple Additive Weighting," Teh. Nusa Mandiri, vol. XIV, no. 1, pp. 49-56, 2017.

[5] I. Saputra, S. I. Sari, and Mesran, "PENERAPAN ELIMINATION AND CHOICE TRANSLATION REALITY ( ELECTRE ) DALAM PENENTUAN KULKAS TERBAIK,” KOMIK (Konferensi Nas. Teknol. Inf. dan Komputer), vol. I, pp. $295-305,2017$.

[6] M. Mesran, R. Rusiana, and M. Sianturi, "Decision Support System for Termination of Employment using Elimination and Choice Translation Reality Method," J. Teknol. dan Sist. Komput., vol. 6, no. 4, p. 135, 2018.

[7] Fadlina, L. T. Sianturi, A. Karim, Mesran, and A. P. U. Siahaan, "Best Student Selection Using Extended Promethee II Method," Int. J. Recent Trends Eng. Res., vol. 3, no. 8, pp. 21-29, 2017.

[8] M. Mesran, S. D. Nasution, S. Syahputra, A. Karim, and E. Purba, "Implementation of the Extended Promethee II in Upgrade Level of Mechanic," Int. J. Sci. Res. Sci. Technol., vol. 4, no. 2, pp. 125-130, 2018.

[9] S. H. Sahir et al., "The Preference Selection Index method in determining the location of used laptop marketing," Int. J. Eng. Technol., vol. 7, no. 3.4 Special Issue 4, 2018.

[10] Mesran, K. Tampubolon, R. D. Sianturi, F. T. Waruwu, and A. P. U. Siahaan, "Determination of Education Scholarship Recipients Using Preference Selection Index," Int. J. Sci. Res. Sci. Technol., vol. 3, no. 6, pp. 230-234, 2017.

[11] M. Mesran, N. Huda, S. N. Hutagalung, K. Khasanah, and A. Iskandar, "SISTEM PENDUKUNG KEPUTUSAN PEMILIHAN SUPERVISOR TERBAIK PADA BAGIAN PERENCANAAN PT. PLN (PERSERO) AREA MEDAN MENERAPKAN PREFERENCE SELECTION INDEX," KOMIK (Konferensi Nas. Teknol. Inf. dan Komputer), vol. 2, no. 1, Oct. 2018.

[12] M. A. Hasma, B. Nadeak, N. Sitompul, and M. Mesran, "Sistem Pendukung Keputusan Penerimaan Instruktur Fitness Menerapkan Metode Additive Ratio Assessment (Aras) (Studi Kasus: Vizta Gym Medan)," KOMIK (Konferensi Nas. Teknol. Inf. dan Komputer), vol. 2, no. 1, pp. 121-129, 2018.

[13] Esra; and AyG̣egül, “AIR CONDITIONER SELECTION PROBLEM WITH COPRAS AND ARAS METHODS,” Manas J. Soc. Stud., vol. 5, no. 2, 2016.

[14] Mesran, J. Afriany, and S. H. Sahir, "Efektifitas Penilaian Kinerja Karyawan Dalam Peningkatan Motivasi Kerja Menerapkan Metode Rank Order Centroid (ROC) dan Additive Ratio Assessment (ARAS)," in Seminar Nasional Riset Information Science (SENARIS), 2019, no. September, pp. 813-821.

[15] D. Nofriansyah and S. Defit, Multi Criteria Decision Making (MCDM) pada Sistem Pendukung Keputusan. 2018.

[16] Kusrini, Konsep dan Aplikasi Sistem Pendukung Keputusan. 2007.

[17] T.-P. Turban, E., Aronson, J., \& Liang, Decision Support Systems And Inteligence System. US: Prentice-Hall, 2005.

[18] N. Astiani, D. Andreswari, and Y. Setiawan, "Aplikasi Sistem Pendukung Keputusan Tanaman Obat Herbal Untuk Berbagai Penyakit Dengan Metode Roc (Rank Order Centroid) Dan Metode Oreste Berbasis Mobile Web,” J. Inform., vol. 12, no. 2, 2016.

[19] R. T. Utami, D. Andreswari, and Y. Setiawan, "Implementasi Metode Simple Additive Weighting (SAW) dengan pembobotan Rank Order Centroid(ROC) Dalam Pengambilan Keputusan Untuk Seleksi Jasa Leasing Mobil,” J. Rekursif, vol. 4, no. 2, pp. 209-221, 2016.

[20] T. widodo Nuri Guntur Perdana, "Sistem Pendukung Keputusan Pemberian Beasiswa Kepada Peserta Didik Baru Menggunakan Metode 
JURNAL MEDIA INFORMATIKA BUDIDARMA, Vol 3, No 4, Oktober 2019

ISSN 2614-5278 (media cetak)

ISSN 2548-8368 (media online)

Hal 376-380 | DOI: 10.30865/mib.v3i4.1511

TOPSIS," in Semantik, 2013, vol. 2013, no. November, pp. 1-8.

[21] P. N. SARI, "SISTEM PENDUKUNG KEPUTUSAN KELAYAKAN PEMBERIANKREDIT DENGAN METODE SIMPLE ADDITIVE WEIGHTING," 2016.

[22] A. W. Oktaputra, 1), and M. K. , Dr., Ir Edi Noersasongko, "SISTEM PENDUKUNG KEPUTUSAN KELAYAKAN PEMBERIAN KREDIT MOTOR MENGGUNAKAN METODE SIMPLE ADDITIVE WEIGHTING PADA PERUSAHAAN LEASING HD FINANCE,” J. SPK Kelayakan Pemberian Kredit Mot., 2014. 